\title{
$\beta$-catenin/Wnt signalling pathway in fibromatosis, metaplastic carcinomas and phyllodes tumours of the breast
}

\author{
Magali Lacroix-Triki ${ }^{1,2, *}$, Felipe C Geyer ${ }^{1, *}$, Maryou B Lambros ${ }^{1}$, Kay Savage ${ }^{1}$, Ian O Ellis ${ }^{3}$, \\ Andrew HS Lee ${ }^{3}$ and Jorge S Reis-Filho ${ }^{1}$ \\ ${ }^{1}$ The Breakthrough Breast Cancer Research Centre, Institute of Cancer Research, London, UK; \\ ${ }^{2}$ Biology-Pathology Medication Department, Institut Claudius Regaud, Toulouse, France and \\ ${ }^{3}$ Division of Pathology, School of Molecular Medical Sciences, University of Nottingham, Nottingham, UK
}

\begin{abstract}
Wnt signalling pathway is known to have a critical role in carcinogenesis and in epithelial-to-mesenchymal transition. Upon Wnt activation, $\beta$-catenin is translocated from the membrane to the cytoplasm and nucleus, where it interacts with transcriptional activators. It has been suggested that various spindle cell lesions of the breast may harbour Wnt pathway activation. Given that $\beta$-catenin nuclear localization constitutes a good surrogate marker of Wnt canonical pathway activation, we have investigated the distribution of $\beta$-catenin in spindle cell lesions of the breast and whether it could be employed in the differential diagnosis of these lesions. A total of $\mathbf{5 2}$ metaplastic breast carcinomas, eight fibromatoses and 23 phyllodes tumours were retrieved from our institutions' archives. We performed immunohistochemistry using two anti- $\beta$-catenin antibodies. In all, three fibromatoses and 21 metaplastic breast carcinomas were subjected to CTNNB1 ( $\beta$-catenin encoding gene) mutation analysis by direct gene sequencing. A good correlation between the two antibodies was observed (Spearman's $r>0.82$, $P<0.001)$. All fibromatoses and $23 \%$ of metaplastic breast carcinomas expressed nuclear $\beta$-catenin. In fibromatosis, $\beta$-catenin was more often diffusely expressed, whereas in metaplastic breast carcinomas, expression was more frequently focal. Membranous $\beta$-catenin expression was significantly lower in spindle cell carcinomas than in other subtypes of metaplastic breast carcinomas. In phyllodes tumours, stromal cells of benign and malignant subtypes displayed nuclear $\beta$-catenin expression in 94 and $57 \%$ of cases, respectively. No CTNNB1 mutation was identified in any of the 21 metaplastic carcinomas analysed, whereas the mutations $45 S>S / P$ and 41T $>T / A$ were found in samples of fibromatosis. In conclusion, $\beta$-catenin nuclear expression is a common feature in fibromatoses and in the stromal component of phyllodes tumours, but may also be observed in metaplastic breast carcinomas. $\beta$-catenin nuclear expression should not be used as a single marker to differentiate fibromatosis from other spindle cell tumours of the breast.
\end{abstract}

Modern Pathology (2010) 23, 1438-1448; doi:10.1038/modpathol.2010.141; published online 6 August 2010

Keywords: breast cancer; catenin; CTNNB1 mutation; immunohistochemistry; spindle cell carcinoma

$\beta$-catenin is a multifunctional protein located to the intracellular side of the cytoplasmic membrane, which has a critical role in cell-to-cell adhesion by linking cadherins to the actin cytoskeleton. ${ }^{1}$ Upon Wnt activation, $\beta$-catenin is translocated from the mem-

Correspondence: Professor JS Reis-Filho, The Breakthrough Breast Cancer Research Centre, Institute of Cancer Research, 237 Fulham Road, London, SW3 6JB, UK, e-mail: Jorge.Reis-Filho@icr.ac.uk or Dr AHS Lee, Nottingham University Hospitals NHS Trust, University of Nottingham, Nottingham, UK, e-mail: Andrew.Lee @nuh.nhs.uk.

*These two authors contributed equally to this work. Received 5 May 2010; revised 14 June 2010; accepted 15 June 2010; published online 6 August 2010 brane to the cytoplasm and nucleus, where it interacts with transcriptional activators to modulate genes such as $c-M Y C,{ }^{2}$ cyclin $D 1^{3,4}$ or NF- $\kappa \mathrm{B}$ target genes. ${ }^{5}$

Cadherin-catenin complexes participate in the normal development and stabilization of the mammary gland architecture, affecting cell fate, polarity and motility. ${ }^{1}$ There are numerous lines of evidence to suggest that a dysfunctional Wnt $/ \beta$-catenin signalling pathway has a critical role in carcinogenesis and in epithelial-to-mesenchymal transition. ${ }^{1,3-7}$ Furthermore, there is evidence that $\beta$-cateninactivating mutations have oncogenic properties. ${ }^{8,9}$

Several studies have investigated $\beta$-catenin expression in spindle cell lesions of the breast, 
including fibromatoses, phyllodes tumours and metaplastic carcinomas. ${ }^{7,10-13}$ Aberrant $\beta$-catenin expression, that is, cytoplasmic and/or nuclear, is typically found in fibromatosis, ${ }^{11}$ however, it has also been described in metaplastic breast carcinomas ${ }^{10}$ and phyllodes tumours. ${ }^{12-15}$ Aberrant $\beta$-catenin expression, and particularly the nuclear localization, which can be detected by immunohistochemistry, constitutes a good surrogate marker of Wnt canonical pathway activation., ${ }^{1,3,10}$ Therefore, and on the basis of its pattern of expression and cellular localization, $\beta$-catenin has been proposed as a useful immunohistochemical marker for the differential diagnosis of spindle cell lesions; ${ }^{16-18}$ however, its use has not been addressed specifically in breast tumours.

$\beta$-catenin gene (CTNNB1) mutations have been shown to be frequently found in fibromatosis of the breast and other anatomical sites (up to $45.5 \%$ of the cases in breast, up to $85 \%$ in sporadic desmoid tumours); these mutations lead to $\beta$-catenin stabilization, nuclear accumulation and Wnt pathway activation. ${ }^{11,19} \beta$-catenin nuclear accumulation, however, does not equate with CTNNB1 mutation. Indeed, in desmoid tumours, either sporadic or associated with familial adenomatous polyposis syndrome, $A P C$ mutations may be the mechanism leading to $\beta$-catenin nuclear expression. ${ }^{11,20}$ In phyllodes tumours, despite evidences of $\beta$-catenin nuclear accumulation, no CTNNB1 mutation has been so far identified in both benign and malignant subtypes, ${ }^{12}$ suggesting that $\beta$-catenin nuclear accumulation in these lesions is driven by mechanisms other than CTNNB1 gene mutations (eg, APC mutation, Wnt5a expression). ${ }^{12}$

In breast cancers, CTNNB1 gene mutations and $\beta$-catenin nuclear expression appear to be less frequent than in other types of carcinomas. ${ }^{6,9}$ Interestingly, Hayes et $a l^{10}$ have recently described the presence of CTNNB1 gene mutations in $\sim 26 \%$ of metaplastic breast carcinomas; however, in an independent study, Hennessy et $a l^{7}$ could not confirm this observation.

The aims of this study were threefold: (1) to address the distribution of $\beta$-catenin expression in metaplastic carcinomas, fibromatosis and phyllodes tumours using two distinct commercially available antibodies; (2) to determine whether this marker could be employed in the differential diagnosis of these lesions; and (3) to investigate whether metaplastic carcinomas harbour CTNNB1 mutations.

\section{Materials and methods}

\section{Case Selection}

A total of 52 metaplastic breast carcinomas, eight fibromatosis and 23 phyllodes tumours of the breast were retrieved from our institutions' archives. Cases were selected consecutively, based on the availability of a formalin-fixed and paraffin-embedded block for the study. All cases were centrally reviewed at least by two pathologists (MLT, FCG, AHL and/or JRF) and classified according to previously published criteria. ${ }^{12,13,21,22}$ Out of the 52 metaplastic breast carcinomas, 22 were classified as spindle cell carcinomas, 17 as carcinomas with squamous metaplasia, and 13 as carcinomas with heterologous elements as previously described. ${ }^{21,23,24}$ Out of the 23 phyllodes tumours of the breast, 16 were classified as benign, four as borderline and three as malignant using previously defined criteria. ${ }^{12,13,25,26}$ This study was approved by the local ethical committees.

\section{Immunohistochemistry}

Immunohistochemistry was performed on $3-\mu$ m-thick representative whole tissue sections from 83 cases, which were mounted on polylysine-coated slides. Two commercially available monoclonal antibodies raised against the C-terminal domain of $\beta$-catenin were used in this study: clone $14 / \beta$-catenin (BD Transduction Laboratories, San Jose, CA, USA) and 17C2 (Novocastra/Leica, Newcastle Upon Tyne, UK), which were used in 1:6000 and 1:100 dilutions, respectively. Heat-induced antigen retrieval was employed for both antibodies: $30 \mathrm{~min}$ in buffer $\mathrm{pH}$ 6.0 in a pre-treatment module (Labvision, Fremont, CA, USA) for $14 / \beta$-catenin antibody and $2 \mathrm{~min}$ in citrate buffer $\mathrm{pH} 6.0$ in a pressure cooker for clone 17C2. Sections were blocked with $1.5 \% \quad \mathrm{H}_{2} \mathrm{O}_{2}$ in methanol for $10 \mathrm{~min}$ and incubated with $\beta$-catenin antibodies for $60 \mathrm{~min}$ at room temperature. Detection was achieved with the Vector avidin-biotin complex (ABC) system (Vector Laboratories, Burlingame, CA, USA) according to the manufacturer's recommendations, using 3,3'-diaminobenzidine (Dako, Glostrup, Denmark) as a chromogenic substrate. Slides were lightly counterstained with haematoxylin. Positive controls (normal breast section) and negative controls (omission of the primary antibody and substitution of the primary antibody by IgG-matched control) were included in each experiment.

$\beta$-catenin immunostains obtained with the two antibodies were analysed independently by two of the authors (MLT and FCG) using the Allred scoring system that combines the staining intensity and the percentage of stained cells (intensity score $0-3+\%$ score 0-5). ${ }^{27}$ For each case, the score was assessed separately for the membranous, cytoplasmic and nuclear reactivity. In phyllodes tumours, the epithelial and spindle cell components were evaluated separately and in metaplastic breast carcinomas with clearly distinguishable morphologically distinct components (ie, carcinomatous and sarcomatous), the two components were also evaluated separately. An Allred score of $>2$ was considered as positive. For membranous staining, cases were further categorized according to the Allred score obtained as displaying a normal expression of $\beta$-catenin (Allred score 7 to 8 ), reduced expression (Allred score 3-6) or no expression (Allred score 0-2). Immunohistochemical analysis with the 
$14 / \beta$-catenin clone was performed with the observers blinded to the results of the analysis of $17 \mathrm{C} 2$ clone.

For a comparison with fibromatosis, we considered the expression patterns and levels of $\beta$-catenin in the stromal cells of phyllodes tumours and in the most abundant component of metaplastic carcinomas. Data analysis was performed with the results obtained with each antibody and also with combined results (ie, for nuclear/cytoplasmic staining, positivity is defined as positive for at least one antibody; for membranous staining, the highest Allred score was taken into account).

\section{Microdissection and DNA Extraction}

Metaplastic carcinomas, one breast fibromatosis and two desmoid tumours were subjected to CTNNB1 sequencing. All cases were microdissected to ensure $>75 \%$ of purity of neoplastic cells. Microdissection was performed with a sterile needle under a stereomicroscope (Olympus SZ61, Tokyo, Japan) from ten consecutive 8- $\mu \mathrm{m}$-thick sections stained with nuclear fast red as previously described. ${ }^{28}$ DNA was extracted using the DNeasy Kit (Qiagen Ltd, Crawley, UK) according to the manufacturer's recommendations. DNA concentration was measured with the PicoGreen assay as per the manufacturer's instructions (Invitrogen, Paisley, UK). ${ }^{28}$ Out of the 52 metaplastic breast carcinomas, microdissection yielded sufficient DNA of optimal quality in 21 samples. One breast fibromatosis and two desmoid tumours yielded sufficient DNA of optimal quality.

\section{CTNNB1 Mutation Analysis}

Sequencing of known mutation hotspots of CTNNB1 on exon $3^{6,9-11,19}$ was performed in 21 metaplastic carcinomas (8 cases with $\beta$-catenin nuclear expression and 13 cases without nuclear expression), one breast fibromatosis and two sporadic desmoid tumours. As a positive control, DNA samples of the HCT116 colon cancer cell line, which is known to harbour CTNNB1 mutation in exon $3,{ }^{29}$ were included in each experiment. The primers used for CTNNB1 sequencing have been previously described. ${ }^{10}$ In all, $50 \mathrm{ng}$ tumour DNA was amplified and sequencing reactions were carried out using the DNA Sequencing Kit BigDye Terminator v 1.1 Cycle Sequencing Ready Reaction Mix (Applied Biosystems, Warrington, UK) as previously described. ${ }^{23}$ Sequences of the forward and reverse strands were analysed with Mutation Surveyor software (Softgenetics, PA, USA). All reactions were carried out in duplicate from the original DNA sample.

\section{Statistical Analysis}

The SPSS statistical software package was used for all statistical analysis. Spearman's correlation coefficient and $\kappa$ agreement value were assessed to analyse the concordance between results from the two $\beta$-catenin antibodies used in parallel in this study. For each antibody, correlations between categorical variables were performed using the $\chi^{2}$ test and Fisher's exact test. A $P$-value of 0.05 was considered as statistically significant.

\section{Results}

\section{Comparison of the Two Anti- $\beta$-Catenin Antibodies}

Two commercially available antibodies raised against $\beta$-catenin, clones $14 / \beta$-catenin and $17 \mathrm{C} 2$, were analysed independently on 83 breast lesions. We observed statistically significant correlations between the two antibodies for the semiquantitative assessment of $\beta$-catenin nuclear, cytoplasmic and membranous expression (Spearman's $r>0.82$, $P<0.0001$ for all comparisons, Table 1). Analysis

Table 1 Comparison of $\beta$-catenin immunostainings in 83 spindle cell lesions of the breast using two commercially available antibodies (clones $14 / \beta$-catenin and 17C2)

\begin{tabular}{|c|c|c|}
\hline & $\begin{array}{c}\text { Clone } 14 / \beta \text {-catenin } \\
(\mathrm{n}=83)\end{array}$ & $\begin{array}{c}\text { Clone 17C2 } \\
\quad(\mathrm{n}=83)\end{array}$ \\
\hline \multicolumn{3}{|c|}{$\beta$-catenin membranous expression } \\
\hline \multicolumn{3}{|c|}{ Allred score } \\
\hline 0 & $38(45.8 \%)$ & $32(38.6 \%)$ \\
\hline 2 & 0 & $4(4.8 \%)$ \\
\hline 3 & $2(2.4 \%)$ & $8(9.6 \%)$ \\
\hline 4 & $3(3.6 \%)$ & $5(6 \%)$ \\
\hline 5 & $5(6 \%)$ & $3(3.6 \%)$ \\
\hline 6 & $10(12 \%)$ & $7(8.4 \%)$ \\
\hline 7 & $8(9.6 \%)$ & $13(15.7 \%)$ \\
\hline 8 & $17(20.6 \%)$ & $11(13.3 \%)$ \\
\hline $\begin{array}{l}\text { Spearman's } r \text {, } \\
\text { two-tailed }\end{array}$ & \multicolumn{2}{|c|}{$0.90(P<0.0001)$} \\
\hline \multicolumn{3}{|c|}{$\beta$-catenin cytoplasmic expression } \\
\hline \multicolumn{3}{|c|}{ Allred score } \\
\hline 0 & $15(18.1 \%)$ & $13(15.7 \%)$ \\
\hline 2 & 0 & $1(1.2 \%)$ \\
\hline 3 & $5(6 \%)$ & $6(7.2 \%)$ \\
\hline 4 & $13(15.7 \%)$ & $22(26.6 \%)$ \\
\hline 5 & $16(19.2 \%)$ & $14(16.8 \%)$ \\
\hline 6 & $22(26.6 \%)$ & $23(27.7 \%)$ \\
\hline 7 & $12(14.4 \%)$ & $4(4.8 \%)$ \\
\hline 8 & 0 & 0 \\
\hline $\begin{array}{l}\text { Spearman's } r \text {, } \\
\text { two-tailed }\end{array}$ & \multicolumn{2}{|c|}{$0.84(P<0.0001)$} \\
\hline \multirow{2}{*}{\multicolumn{3}{|c|}{$\beta$-catenin nuclear expression }} \\
\hline & & Allred score \\
\hline 0 & $45(54.3 \%)$ & $39(47.1 \%)$ \\
\hline 2 & $3(3.6 \%)$ & $9(10.9 \%)$ \\
\hline 3 & $9(10.9 \%)$ & $10(12 \%)$ \\
\hline 4 & $8(9.6 \%)$ & $10(12 \%)$ \\
\hline 5 & $4(4.8 \%)$ & $12(14.4 \%)$ \\
\hline 6 & $12(14.4 \%)$ & $3(3.6 \%)$ \\
\hline 7 & $2(2.4 \%)$ & 0 \\
\hline 8 & 0 & 0 \\
\hline $\begin{array}{l}\text { Spearman's } r \text {, } \\
\text { two-tailed }\end{array}$ & \multicolumn{2}{|c|}{$0.83(P<0.0001)$} \\
\hline
\end{tabular}


Table $2 \beta$-catenin expression in metaplastic breast carcinomas $(n=52)$

\begin{tabular}{|c|c|c|c|c|c|c|c|}
\hline & \multirow[b]{3}{*}{$\mathrm{n}$} & \multicolumn{2}{|c|}{ Clone $14 / \beta$-catenin } & \multicolumn{2}{|c|}{ Clone $17 C 2$} & \multicolumn{2}{|c|}{ Combined $^{\mathrm{a}}$} \\
\hline & & \multicolumn{2}{|c|}{$\beta$-catenin nuclear } & \multicolumn{2}{|c|}{$\beta$-catenin nuclear } & \multicolumn{2}{|c|}{$\beta$-catenin nuclear } \\
\hline & & $\begin{array}{c}\text { Positive } \\
(\text { Allred > 2) }\end{array}$ & $\begin{array}{c}\text { Negative } \\
\text { (Allred 0-2) }\end{array}$ & $\begin{array}{c}\text { Positive } \\
(\text { Allred }>2)\end{array}$ & $\begin{array}{c}\text { Negative } \\
\text { (Allred 0-2) }\end{array}$ & $\begin{array}{c}\text { Positive } \\
(\text { Allred > 2) }\end{array}$ & $\begin{array}{c}\text { Negative } \\
\text { (Allred 0-2) }\end{array}$ \\
\hline $\begin{array}{l}\text { Squamous } \\
\text { metaplasia }\end{array}$ & 17 & $3(17.6 \%)$ & $14(82.4 \%)$ & $3(17.6 \%)$ & $14(82.4 \%)$ & $5(29.4 \%)$ & $12(70.6 \%)$ \\
\hline $\begin{array}{l}\text { Heterologous } \\
\text { elements }\end{array}$ & 13 & $2(15.4 \%)$ & $11(84.6 \%)$ & $1(7.7 \%)$ & $12(92.3 \%)$ & $2(15.4 \%)$ & $11(84.6 \%)$ \\
\hline Spindle cell & 22 & $4(18.2 \%)$ & $18(81.8 \%)$ & $4(18.2 \%)$ & $18(81.8 \%)$ & $5(22.7 \%)$ & $17(77.3 \%)$ \\
\hline Total & 52 & $9(17.3 \%)$ & $43(82.7 \%)$ & $8(15.4 \%)$ & $44(84.6 \%)$ & $12(23 \%)$ & $40(77 \%)$ \\
\hline $\begin{array}{l}\text { Fisher's test, } \\
3 \times 2\end{array}$ & \multicolumn{3}{|c|}{$P=0.999$} & \multicolumn{2}{|c|}{$P=0.788$} & \multicolumn{2}{|c|}{$P=0.651$} \\
\hline
\end{tabular}

$\beta$-catenin cytoplasmic

$\mathrm{n}$

$\begin{array}{cc}\text { Positive } & \text { Negative } \\ (\text { Allred }>2) & \text { (Allred 0-2) }\end{array}$

Squamous $\quad 17 \quad 17(100 \%)$

metaplasia

Heterologous $13 \quad 13(100 \%)$

elements

Spindle cell $\quad 22 \quad 22(100 \%)$

Total $\quad 52 \quad 52(100 \%)$

Fisher's test,

$3 \times 2$
NP

$\beta$-catenin membranous

\begin{tabular}{|c|c|}
\hline $\begin{array}{c}\text { Negative } \\
\text { (Allred 0-2) }\end{array}$ & $\begin{array}{c}\text { Positive } \\
\text { (Allred }>2\end{array}$ \\
\hline 0 & $17(100 \%)$ \\
\hline 0 & $13(100 \%)$ \\
\hline 0 & $22(100 \%)$ \\
\hline 0 & $52(100 \%)$ \\
\hline
\end{tabular}

$\beta$-catenin cytoplasmic

(Allred 0-2)

NP

$\beta$-catenin cytoplasmic

$\begin{array}{cc}\text { Positive } & \text { Negative } \\ (\text { Allred }>2) & (\text { Allred } 0-2)\end{array}$

$17(100 \%)$
$13(100 \%)$
$22(100 \%)$
$52(100 \%)$

$\begin{array}{ll}0 & 17(100 \%) \\ 0 & 13(100 \%) \\ 0 & 22(100 \%) \\ 0 & 52(100 \%)\end{array}$

$\begin{array}{ll} & 0 \\ & 0 \\ & \\ & 0 \\ \text { NP } & 0\end{array}$

0

0

0

$\beta$-catenin membranous

\begin{tabular}{|c|c|c|c|c|c|c|c|c|c|c|}
\hline & & $\begin{array}{c}\text { Normal } \\
\text { (Allred 7-8) }\end{array}$ & $\begin{array}{c}\text { Reduced } \\
\text { (Allred 3-6) }\end{array}$ & $\begin{array}{c}\text { Negative } \\
\text { (Allred 0-2) }\end{array}$ & $\begin{array}{c}\text { Normal } \\
\text { (Allred 7-8) }\end{array}$ & $\begin{array}{c}\text { Reduced } \\
\text { (Allred 3-6) }\end{array}$ & $\begin{array}{c}\text { Negative } \\
\text { (Allred } 0-2 \text { ) }\end{array}$ & $\begin{array}{c}\text { Normal } \\
\text { (Allred 7-8) }\end{array}$ & $\begin{array}{l}\text { Reduced } \\
\text { (Allred 3-6) }\end{array}$ & $\begin{array}{c}\text { Negative } \\
\text { (Allred 0-2) }\end{array}$ \\
\hline $\begin{array}{l}\text { Squamous } \\
\text { metaplasia }\end{array}$ & 17 & $12(70.6 \%)$ & $5(29.4 \%)$ & 0 & $12(70.6 \%)$ & $5(29.4 \%)$ & 0 & $14(82.3 \%)$ & $3(17.7 \%)$ & 0 \\
\hline $\begin{array}{l}\text { Heterologous } \\
\text { elements }\end{array}$ & 13 & $7(53.8 \%)$ & $6(46.2 \%)$ & 0 & 7 (53.8 \%) & $6(46.2 \%)$ & 0 & $8(61.5 \%)$ & $5(38.5 \%)$ & 0 \\
\hline Spindle cell & 22 & $6(27.3 \%)$ & $9(40.9 \%)$ & $7(31.8 \%)$ & $5(22.7 \%)$ & $12(54.6 \%)$ & $5(22.7 \%)$ & $6(27.3 \%)$ & $13(59.1 \%)$ & $3(13.6 \%)$ \\
\hline Total & 52 & $25(48.0 \%)$ & $20(38.5 \%)$ & $7(13.5 \%)$ & $24(46.2 \%)$ & $23(44.2 \%)$ & $5(9.6 \%)$ & $28(53.8 \%)$ & $21(40.4 \%)$ & $3(5.8 \%)$ \\
\hline $\begin{array}{l}\text { Fisher's test, } \\
3 \times 3\end{array}$ & & & $P=0.009$ & & & $P=0.011$ & & & $P=0.005$ & \\
\hline
\end{tabular}

$3 \times 3$

NP, not performed (not computed as the data are constant).

${ }^{a}$ Combines the data obtained with both antibodies (ie, for nuclear/cytoplasmic staining, positivity is defined as positive for at least 1 antibody; for membranous staining, the highest Allred score was taken into account).

of agreement between the two antibodies for nuclear, cytoplasmic and membranous expression revealed nearly perfect agreement for all comparisons, ${ }^{30}$ with $K$ scores of 0.88 (95\% confidence intervals 0.78-0.98), 0.89 (95\% confidence intervals 0.73-1.01) and 0.85 (95\% confidence intervals 0.740.97 ) when positive (Allred score $>2$ ) vs negative (Allred score $\leq 2$ ) categories were used.

\section{$\beta$-Catenin Expression in Metaplastic Carcinomas}

By combining the results of both antibodies, 49 out of 52 metaplastic breast carcinomas displayed $\beta$ catenin membranous expression (Table 2). $\beta$-catenin membranous expression was significantly lower in spindle cell carcinomas than in carcinomas with squamous metaplasia and in carcinomas with hetero- logous elements (Fisher's exact test $3 \times 3$, two-tailed $P=0.005$ when combining both antibodies; Table 2 and Figure 1). In seven cases exhibiting at least two morphologically distinct components in the same sections, the sarcomatous elements consistently displayed loss or reduction of membranous expression when compared with the epithelial component (Fisher's exact test, two-tailed, $P=0.0005$ and $P=0.004$ for clones 14/ $\beta$-catenin and 17C2, respectively; Table 3).

Analysis of $\beta$-catenin nuclear expression revealed $17 \%(9 / 52)$ and $15 \%(8 / 52)$ of cases displaying nuclear expression with the $14 / \beta$-catenin and $17 \mathrm{C} 2$ clones, respectively. When results from both antibodies were combined (ie, a case scored as positive for only one antibody was considered positive), $23 \%(12 / 52$ cases) of metaplastic breast carcinomas displayed $\beta$-catenin nuclear expression (Table 2 and Figure 2). Regardless of the antibody used, no 

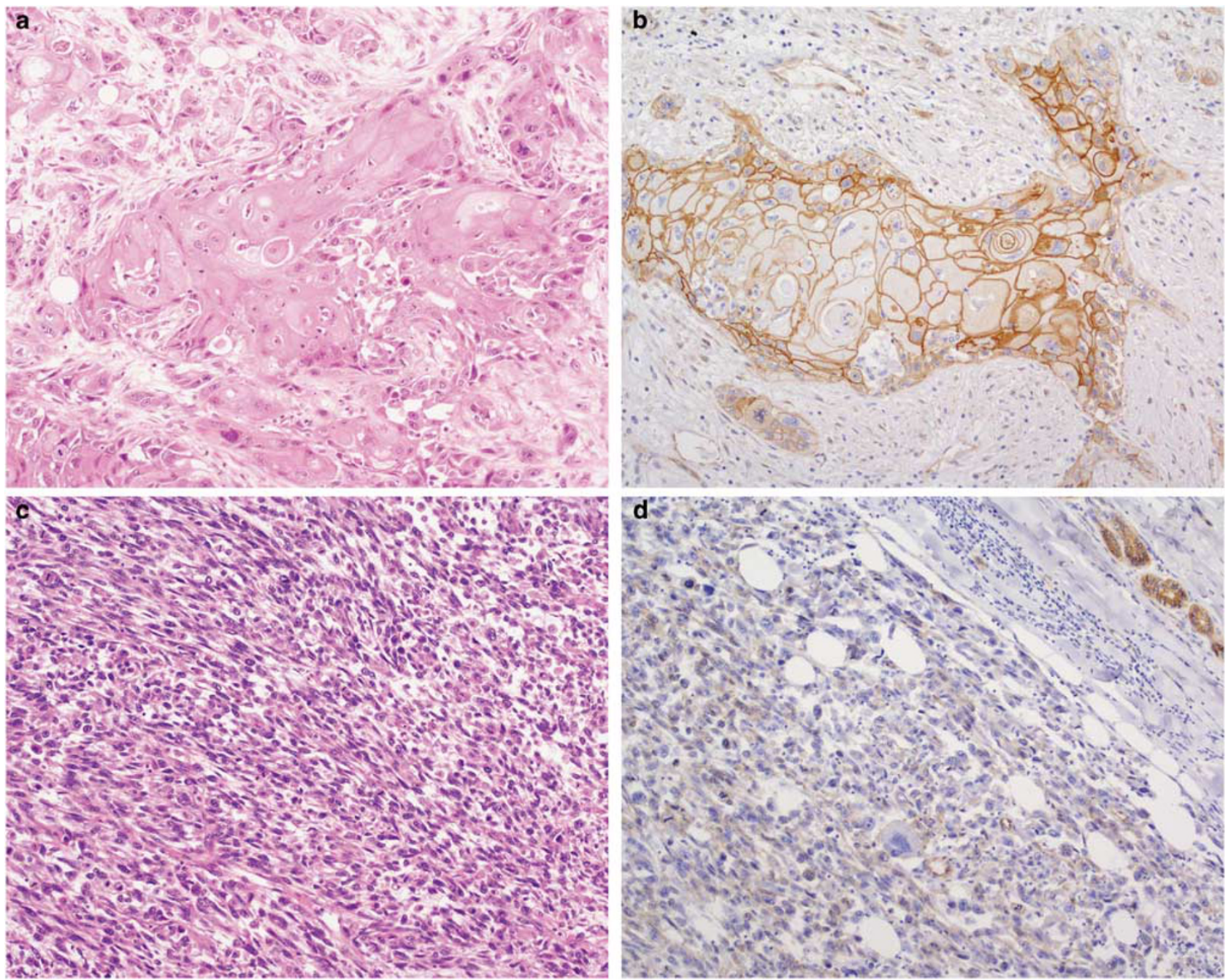

Figure $1 \beta$-catenin membranous expression in metaplastic breast carcinomas. A carcinoma with squamous metaplasia (a) displaying strong $\beta$-catenin reactivity at the membrane of the majority of the neoplastic cells (b). A spindle cell carcinoma (c) displaying lack/ reduction of $\beta$-catenin membranous expression (d). Both cases lacked $\beta$-catenin nuclear staining.

association between the subtypes of metaplastic breast carcinomas and $\beta$-catenin nuclear expression was found (Table 2 and Figure 2). In addition, in the seven cases where two morphologically distinct components were evaluated, $\beta$-catenin nuclear accumulation was not significantly associated with any of the components (Table 3). For both antibodies, all positive cases for nuclear expression displayed $<33 \%$ of positive neoplastic cells, with variable intensity, never exceeding an Allred score of 5 (Table 4).

\section{$\beta$-Catenin Expression in Fibromatosis}

With both antibodies, all fibromatoses analysed $(n=8)$ expressed nuclear $\beta$-catenin in at least $33 \%$ of neoplastic cells, with variable intensity, and lacked any membranous expression. Cytoplasmic staining was observed in 100 and $87 \%$ of cases with $14 / \beta$-catenin and $17 \mathrm{C} 2$ clones, respectively (Table 5 and Figure 3).

\section{$\beta$-Catenin Expression in Phyllodes Tumours}

In all phyllodes tumours, membranous staining was observed with both antibodies only in the epithelial component (Table 5 and Figure 4). Nuclear expression was found in epithelial and stromal cell components in up to 75 and $94 \%$, respectively, of benign phyllodes tumours (Figure 4 and Table 5), with a preferential localization of the nuclear-positive stromal cells around the epithelial structures. In accord with the results described by Sawyer et $a l^{12}{ }^{12}$ a trend for a lower prevalence of nuclear expression in stromal cells of borderline/malignant phyllodes tumours than in benign phyllodes tumours was found when the $14 / \beta$-catenin clone was employed (Fisher's exact test, two-tailed $P=0.067$; Figure 4 and Table 5).

\section{CTNNB1 Mutation Analysis in Metaplastic Carcinomas}

To investigate the presence of CTNNB1 mutations in metaplastic breast cancers, we sequenced eight 
Table $3 \beta$-catenin expression in metaplastic breast carcinomas $(n=7)$ displaying two morphologically distinct tumour components

\begin{tabular}{|c|c|c|c|c|c|}
\hline & \multirow[b]{2}{*}{ MBC subtype } & \multicolumn{2}{|c|}{ Clone $14 / \beta$-catenin } & \multicolumn{2}{|c|}{ Clone $17 \mathrm{C} 2$} \\
\hline & & $\begin{array}{c}\text { Carcinomatous } \\
\text { component } \\
\text { (Allred score) }\end{array}$ & $\begin{array}{c}\text { Sarcomatous } \\
\text { component } \\
\text { (Allred score) }\end{array}$ & $\begin{array}{c}\text { Carcinomatous } \\
\text { component } \\
\text { (Allred score) }\end{array}$ & $\begin{array}{c}\text { Sarcomatous } \\
\text { component } \\
\text { (Allred score) }\end{array}$ \\
\hline \multicolumn{6}{|l|}{ Membranous expression } \\
\hline Case 1 & Spindle cell & 7 & 0 & 5 & 3 \\
\hline Case 6 & Squamous metaplasia & 8 & 0 & 8 & 3 \\
\hline Case 16 & Squamous metaplasia & 8 & 3 & 8 & 3 \\
\hline Case 31 & Heterologous elements & 8 & 3 & 8 & 3 \\
\hline Case 33 & Spindle cell & 7 & 0 & 7 & 0 \\
\hline Case 45 & Spindle cell & 8 & 0 & 7 & 0 \\
\hline Case 46 & Spindle cell & 7 & 0 & 7 & 3 \\
\hline $\begin{array}{l}\text { Fisher's exact test } \\
\text { (normal vs reduced/negative) }^{\mathrm{a}}\end{array}$ & & \multicolumn{2}{|c|}{$P=0.0005$} & \multicolumn{2}{|c|}{$P=0.004$} \\
\hline \multicolumn{6}{|l|}{ Cytoplasmic expression } \\
\hline Case 1 & Spindle cell & 6 & 4 & 6 & 6 \\
\hline Case 6 & Squamous metaplasia & 6 & 5 & 6 & 5 \\
\hline Case 16 & Squamous metaplasia & 7 & 5 & 6 & 4 \\
\hline Case 31 & Heterologous elements & 6 & 5 & 6 & 4 \\
\hline Case 33 & Spindle cell & 7 & 6 & 6 & 5 \\
\hline Case 45 & Spindle cell & 5 & 5 & 5 & 5 \\
\hline Case 46 & Spindle cell & 5 & 5 & 5 & 4 \\
\hline $\begin{array}{l}\text { Fisher's exact test } \\
\text { (positive vs negative) }^{\mathrm{b}}\end{array}$ & & \multicolumn{2}{|c|}{ NP } & \multicolumn{2}{|c|}{$\mathrm{NP}$} \\
\hline \multicolumn{6}{|l|}{ Nuclear expression } \\
\hline Case 1 & Spindle cell & 0 & 0 & 0 & 0 \\
\hline Case 6 & Squamous metaplasia & 0 & 0 & 0 & 4 \\
\hline Case 16 & Squamous metaplasia & 0 & 0 & 0 & 0 \\
\hline Case 31 & Heterologous elements & 0 & 0 & 0 & 0 \\
\hline Case 33 & Spindle cell & 0 & 2 & 0 & 2 \\
\hline Case 45 & Spindle cell & 0 & 2 & 0 & 0 \\
\hline Case 46 & Spindle cell & 0 & 3 & 0 & 0 \\
\hline $\begin{array}{l}\text { Fisher's exact test } \\
\text { (positive vs negative) }^{\mathrm{b}}\end{array}$ & & \multicolumn{2}{|c|}{$P=0.999$} & \multicolumn{2}{|c|}{$P=0.999$} \\
\hline
\end{tabular}

MBC, metaplastic breast carcinoma; NP, not performed (not computed as the data are constant).

${ }^{\mathrm{a}}$ Normal: Allred score 7-8; reduced: Allred score 3-6; negative: Allred score 0-2.

${ }^{\mathrm{b}}$ Positive: Allred score 3-8; negative: Allred score 0-2.

metaplastic carcinomas with $\beta$-catenin nuclear expression and 13 cases without $\beta$-catenin nuclear expression. Positive controls, included in each experiment, showed the expected presence of the previously reported CTNNB1 mutation in exon 3 (deletion of codon 45) in the HCT116 colo-rectal cell line. ${ }^{29}$ In addition, to test the accuracy of the CTNNB1 mutation analysis on formalin-fixed and paraffin-embedded tissues, a case of breast fibromatosis from this cohort and two sporadic desmoid tumours were included in the analysis and were found to harbour activating CTNNB1 mutations on exon 3 (25195T $>$ TC:45S $>$ S/P in breast fibromatosis, Figure 3b; 25183A $>$ AG:41T $>$ T/A in both desmoid tumours), which have been previously described in sporadic desmoid tumours. ${ }^{19}$ None of the 21 metaplastic carcinomas analysed here harboured any exon 3 CTNNB1 gene mutation. In two cases, the distinct components (ductal and spindle in one case; spindle, rhabdoid and chondroid in another case) were separately microdissected and subjected to CTNNB1 sequencing analysis, but no mutation was found.

\section{Discussion}

$\beta$-catenin nuclear expression in neoplastic lesions constitutes a surrogate marker of Wnt pathway activation and may also suggest the presence of mutations of the CTNNB1 gene and other genes in the Wnt pathway (eg, $A P C$ ). Given the high prevalence of $C T N N B 1$ and $A P C$ gene mutations in fibromatoses from various anatomical sites including breast, ${ }^{11,19,20}$ $\beta$-catenin immunohistochemical assessment has been proposed as a useful tool in the differential diagnosis between fibromatosis and other spindle cell lesions of the breast. ${ }^{16-18}$ Here, we demonstrate that although fibromatosis consistently express $\beta$-catenin nuclear expression, $23 \%$ of metaplastic breast carcinomas and the stromal cells of $93 \%$ of phyllodes tumours also display $\beta$-catenin nuclear expression. 

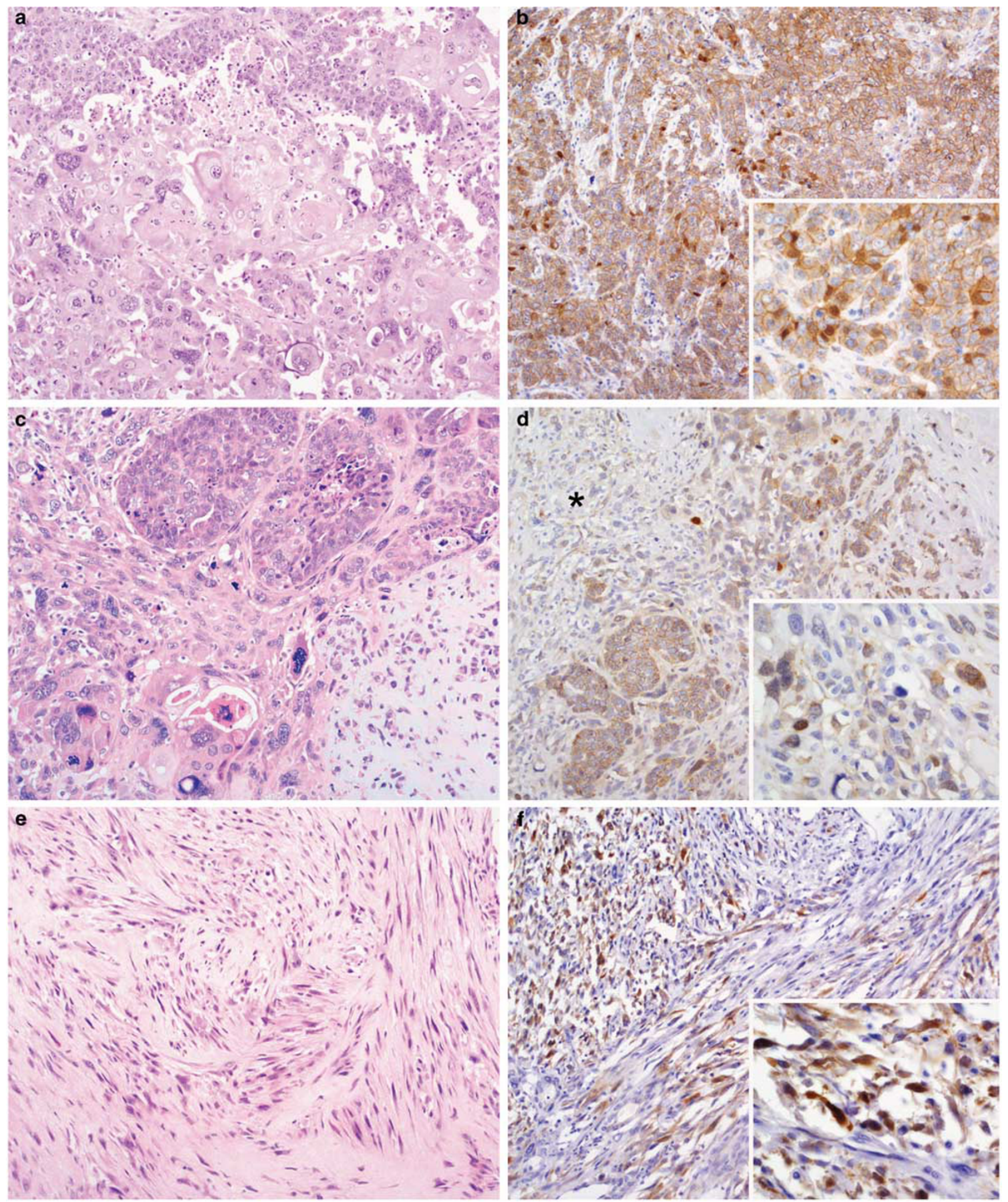

Figure $2 \beta$-catenin nuclear expression in metaplastic breast carcinomas. A carcinoma with squamous metaplasia (a) displaying focal strong nuclear $\beta$-catenin staining (b). A carcinoma with heterologous elements (c) displaying focal weak-to-moderate nuclear expression of $\beta$-catenin (d). A spindle cell carcinoma (e) displaying strong $\beta$-catenin nuclear reactivity (f). Note that the carcinoma with squamous metaplasia and the carcinomatous component of the carcinoma with heterologous elements showed membranous $\beta$-catenin expression whereas the sarcomatous component of the carcinoma with heterologous elements (d, asterisk) and the spindle cell carcinoma showed reduction/lack of $\beta$-catenin membranous expression. 
Fibromatosis, phyllodes tumours and a subset of metaplastic breast carcinomas may in some instances give rise to a diagnostic difficulty, especially in core-

Table 4 Summary of Allred scores for nuclear $\beta$-catenin expression in 52 metaplastic carcinomas according to the antibody clones $14 / \beta$-catenin and $17 \mathrm{C} 2$

\begin{tabular}{|c|c|c|}
\hline Allred score & $\begin{array}{l}\text { Clone } 14 / \beta \text {-catenin } \\
\text { Number of cases }\end{array}$ & $\begin{array}{c}\text { Clone } 17 C 2 \\
\text { Number of cases }\end{array}$ \\
\hline \multicolumn{3}{|l|}{ Negative } \\
\hline 0 & 42 & 36 \\
\hline 2 & 1 & 8 \\
\hline Total & 43 & 44 \\
\hline \multicolumn{3}{|l|}{ Positive } \\
\hline 3 & 6 & 2 \\
\hline 4 & 2 & 5 \\
\hline 5 & 1 & 1 \\
\hline 6 & 0 & 0 \\
\hline 7 & 0 & 0 \\
\hline 8 & 0 & 0 \\
\hline Total & 9 & 8 \\
\hline
\end{tabular}
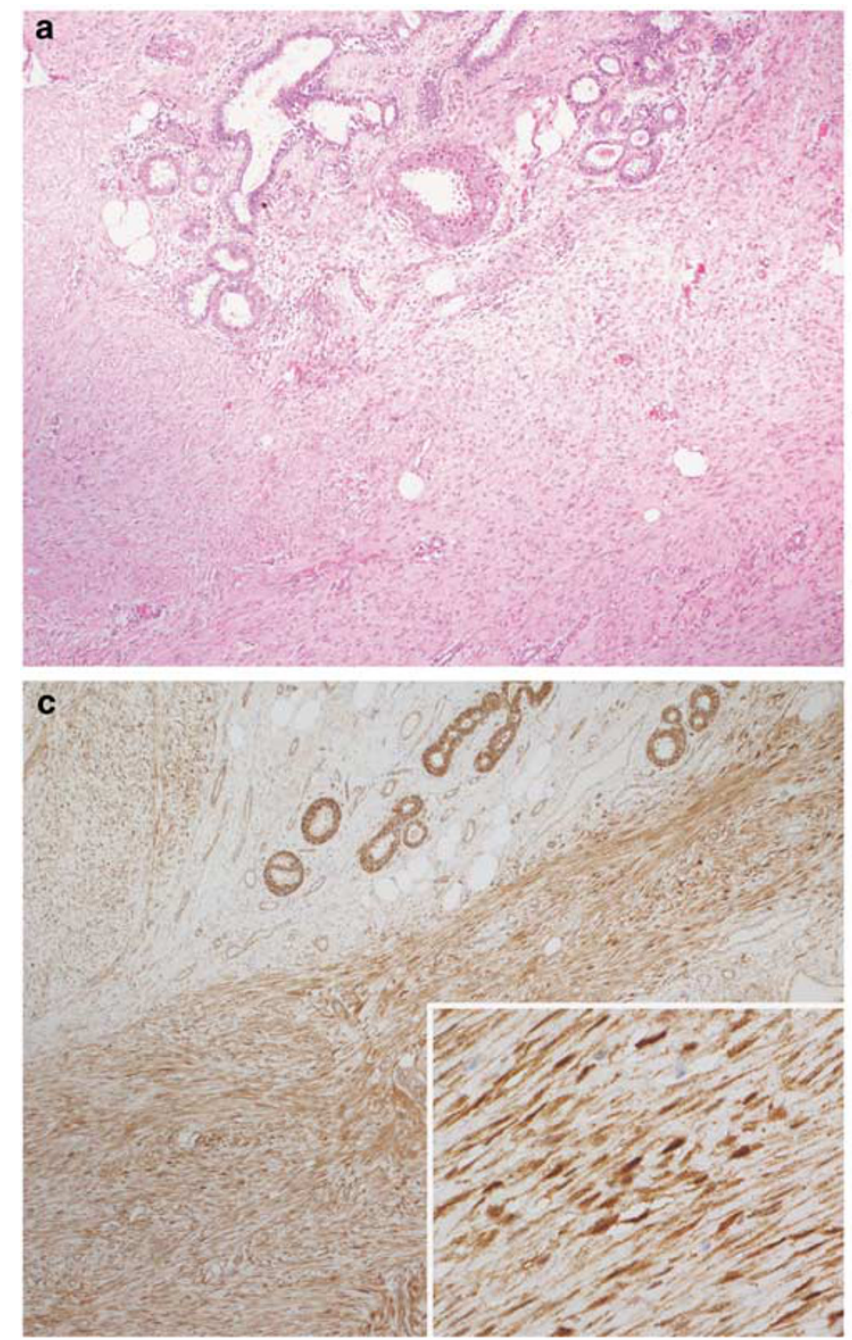

needle biopsies that may not be representative of the whole lesion. ${ }^{16}$ In our series, all fibromatosis displayed diffuse $\beta$-catenin nuclear expression and lack of membrane expression. It should be pointed out that a previous study on a larger cohort of 33 breast fibromatoses reported that up to $18 \%$ of the cases failed to display nuclear expression. ${ }^{11} \beta$-catenin cytoplasmic expression is often observed in fibromatosis; however, fibromatosis neoplastic cells consistently lack membranous expression (our results and those of Abraham et $a l^{11}$ ). Likewise, the stromal component of phyllodes tumours do not express $\beta$-catenin at the membrane and may harbour nuclear reactivity in up to $93 \%$ of the cases described in this study. Therefore, given that the patterns of $\beta$-catenin expression in fibromatosis and a subset of phyllodes tumours and metaplastic breast carcinomas clearly overlap, the differential diagnosis between these three spindle cell lesions should not rely solely on the use of $\beta$-catenin immunohistochemistry.

A previous study ${ }^{10}$ described aberrant $\beta$-catenin expression in $92 \%$ of metaplastic carcinomas and

b

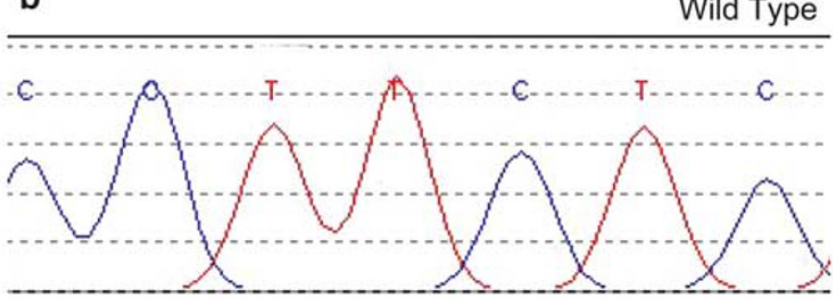

\section{Fibromatosis}
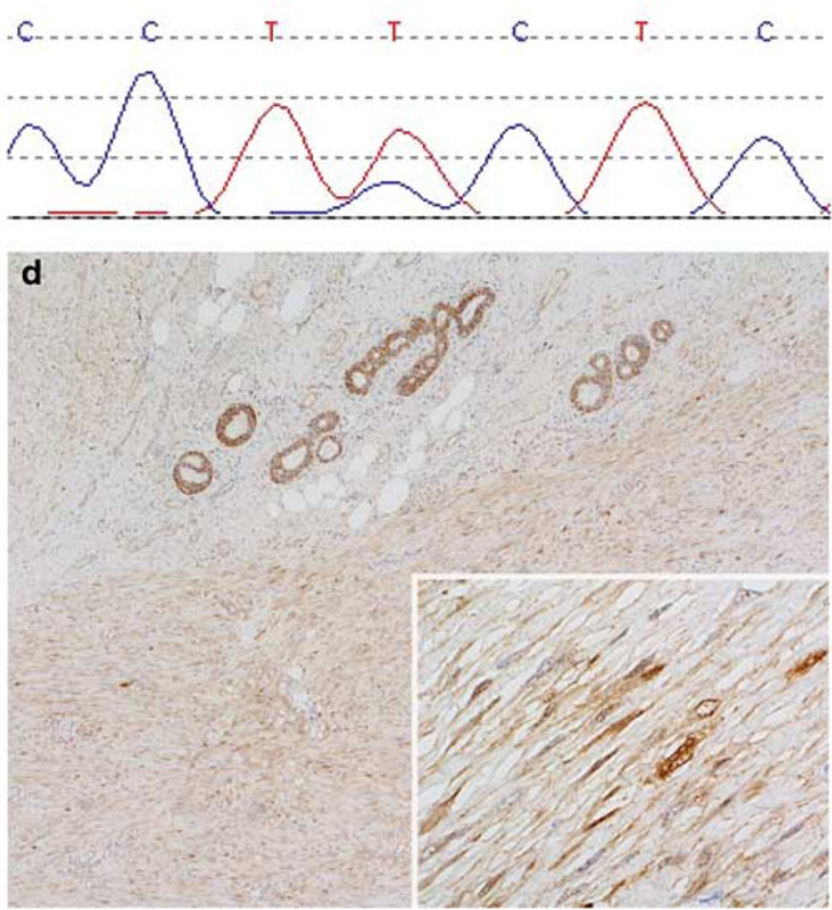

Figure $3 \beta$-catenin expression and CTNNB1 exon 3 mutation in breast fibromatosis. A breast fibromatosis (a) adjacent to an entrapped normal breast lobule, which harboured an activating 25195T > TC:45S > S/P CTNNB1 exon 3 mutation (b) and cytoplasmic and nuclear $\beta$-catenin expression with clones 14/ $\beta$-catenin (c) and 17C2 (d). No membranous staining was detected with any of the antibodies tested. 

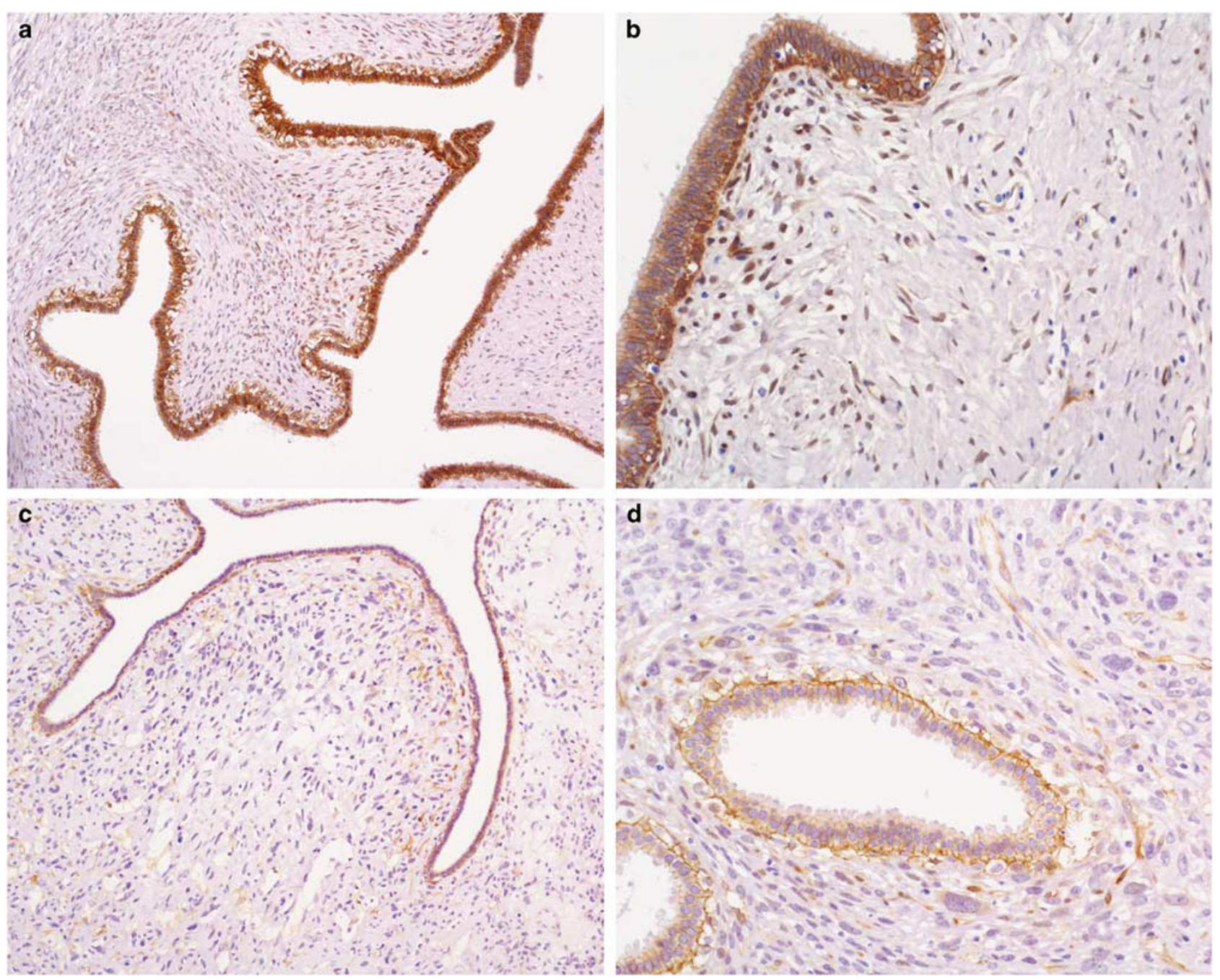

Figure $4 \beta$-catenin expression in phyllodes tumours of the breast. A benign (a, b) and a malignant (c, d) phyllodes tumours. Membranous and nuclear $\beta$-catenin expression was observed, respectively, in epithelial and stromal cells of both lesions. Note that nuclear expression was predominantly found in stromal cells surrounding the epithelial cells. In addition, less stromal cells displayed nuclear expression in the malignant phyllodes tumour.

identified exon 3 CTNNB1 gene mutations in $26 \%$ of cases. Using two antibodies against $\beta$-catenin, in this study we demonstrate that more than a third $(46 \%)$ of metaplastic breast carcinomas displayed reduction or lack of $\beta$-catenin membrane staining and that abnormal cytoplasmic and/ or nuclear staining was found in $100 \%$ of cases. Although these results suggest that Wnt pathway may be dysfunctional in the vast majority of metaplastic breast cancers, it should be noted that the mechanisms leading to $\beta$-catenin activation in these lesions remain contentious. In contrast with the results from Hayes et $a l^{10}$ and in agreement with Hennessy et al, ${ }^{7}$ no exon 3 CTNNB1 gene mutations were identified in our analysis of microdissected metaplastic breast carcinomas. The stark contrast between the results by Hayes et $a l^{10}$ and the combined results of Hennessy et $\mathrm{al}^{7}$ and those presented in this study may stem from different case selections, different methods for gene sequencing and different approaches for sample accrual. Importantly, in this study, all cases were microdissected and sequenced in duplicate, minimizing the artefacts induced by formalin fixation. Furthermore, in two cases, morphologically distinct components of metaplastic breast carcinomas were microdissected separately and no mutations were identified.

In this study we demonstrate that spindle cell metaplastic breast carcinomas display significantly lower levels of $\beta$-catenin membrane staining than other subtypes of metaplastic cancers. $\mathrm{We}^{31,32}$ and others ${ }^{7,33,34}$ have previously demonstrated that metaplastic cancers display transcriptomic features suggestive of an epithelial-to-mesenchymal transition phenotype. Given the role of the Wnt pathway in epithelial-to-mesenchymal transition, our results are consistent with the hypothesis that at least a subgroup of metaplastic breast cancers have features of epithelial-to-mesenchymal transition and that Wnt pathway activation may have a role in this 
Table $5 \beta$-catenin expression in fibromatosis $(n=8)$ and in the distinct components of phyllodes tumours $(n=23$, benign $n=16$, borderline/malignant $n=7$ ).

\begin{tabular}{|c|c|c|}
\hline & $\begin{array}{l}\text { Clone 14/ } \\
\beta \text {-catenin }\end{array}$ & Clone 17C2 \\
\hline \multicolumn{3}{|l|}{ Fibromatosis $(\mathrm{n}=8)$} \\
\hline \multicolumn{3}{|l|}{ Nuclear } \\
\hline Positive & $8(100 \%)$ & $8(100 \%)$ \\
\hline Negative & 0 & 0 \\
\hline Median Allred score (range) & $6(4-7)$ & $5(4-6)$ \\
\hline \multicolumn{3}{|l|}{ Cytoplasmic } \\
\hline Positive & $8(100 \%)$ & $7(87.5 \%)$ \\
\hline Negative & 0 & $1(12.5 \%)$ \\
\hline Median Allred score (range) & $4(3-7)$ & $4.5(2-5)$ \\
\hline \multicolumn{3}{|l|}{ Membranous } \\
\hline Normal & 0 & 0 \\
\hline Reduced & 0 & 0 \\
\hline Negative & $8(100 \%)$ & $8(100 \%)$ \\
\hline \multicolumn{3}{|l|}{ Phyllodes tumours $(\mathrm{n}=23$ ) } \\
\hline \multicolumn{3}{|l|}{ Nuclear } \\
\hline \multicolumn{3}{|l|}{ Spindle cell component } \\
\hline \multicolumn{3}{|l|}{ Benign PTs } \\
\hline Positive & $15(93.7 \%)$ & $15(93.7 \%)$ \\
\hline Negative & $1(6.3 \%)$ & $1(6.3 \%)$ \\
\hline \multicolumn{3}{|l|}{ Borderline/malignant PTs } \\
\hline Positive & $4(57.1 \%)$ & $5(71.4 \%)$ \\
\hline Negative & $3(42.9 \%)$ & $2(28.6 \%)$ \\
\hline Fisher's exact test, two-tailed & $P=0.0671$ & $P=0.209$ \\
\hline \multicolumn{3}{|l|}{ Epithelial component } \\
\hline \multicolumn{3}{|l|}{ Benign PTs } \\
\hline Positive & $12(75 \%)$ & $9(56.2 \%)$ \\
\hline Negative & $4(25 \%)$ & $7(43.8 \%)$ \\
\hline \multicolumn{3}{|l|}{ Borderline/malignant PTs } \\
\hline Positive & $3(42.9 \%)$ & $3(42.9 \%)$ \\
\hline Negative & $4(57.1 \%)$ & $4(57.1 \%)$ \\
\hline Fisher's exact test, two-tailed & $P=0.182$ & $P=0.667$ \\
\hline \multicolumn{3}{|l|}{ Cytoplasmic } \\
\hline \multicolumn{3}{|l|}{ Spindle cell component } \\
\hline \multicolumn{3}{|l|}{ Benign PTs } \\
\hline Positive & $5(31.2 \%)$ & $6(37.5 \%)$ \\
\hline Negative & $11(68.8 \%)$ & $10(62.5 \%)$ \\
\hline \multicolumn{3}{|l|}{ Borderline/malignant PTs } \\
\hline Positive & $3(42.9 \%)$ & $4(57.1 \%)$ \\
\hline Negative & $4(57.1 \%)$ & $3(42.9 \%)$ \\
\hline Fisher's exact test, two-tailed & $P=0.657$ & $P=0.650$ \\
\hline \multicolumn{3}{|l|}{ Epithelial component } \\
\hline Positive & $23(100 \%)$ & $23(100 \%)$ \\
\hline Negative & 0 & 0 \\
\hline \multicolumn{3}{|l|}{ Membranous } \\
\hline Spindle cell component & & \\
\hline Normal & 0 & 0 \\
\hline Reduced & 0 & 0 \\
\hline Negative & $23(100 \%)$ & $23(100 \%)$ \\
\hline Epithelial component & & \\
\hline Benign PTs & & \\
\hline Normal & $12(75 \%)$ & $10(62.5 \%)$ \\
\hline Reduced & $4(25 \%)$ & $6(37.5 \%)$ \\
\hline Negative & 0 & 0 \\
\hline Borderline/malignant PTs & & \\
\hline Normal & $4(57.1 \%)$ & $2(28.6 \%)$ \\
\hline Reduced & $3(42.9 \%)$ & $5(71.4 \%)$ \\
\hline Negative & 0 & 0 \\
\hline Fisher's exact test, $2 \times 3$ & $P=0.625$ & $P=0.193$ \\
\hline
\end{tabular}

PTs, phyllodes tumours. process. Given the apparent lack of mutations in the exon 3 hotspot in this series and in the study by Hennessy et $a l^{7}$ our results suggest that $\beta$-catenin aberrant expression in metaplastic breast carcinomas may stem from mutations affecting other exons of the CTNNB1 gene or other genes in the Wnt pathway (eg, the APC gene). Alternatively, $\beta$-catenin aberrant expression and Wnt pathway activation in these tumours may be the consequence of a global epithelial-to-mesenchymal transition programme..$^{33,34}$

Consistent with the hypothesis of $\beta$-catenin aberrant expression and epithelial-to-mesenchymal transition, in seven biphasic metaplastic lesions, we observed a lack/reduction of membranous $\beta$-catenin expression to be significantly associated with the sarcomatous component (Table 3). Furthermore, nuclear $\beta$-catenin expression was restricted to the sarcomatous counterpart in two of these cases (one with each antibody); however, no statistically significant difference was observed in the prevalence of $\beta$-catenin nuclear expression in the sarcomatous and carcinomatous components. Therefore, in some cases, activation of the $\beta$-catenin/Wnt pathway is coincidental with the morphological characteristics of epithelial-to-mesenchymal transition, which may indicate some degree of clonal divergence between the morphologically distinct components of metaplastic breast carcinomas. Likewise, we have previously shown that intratumour morphological heterogeneity in some metaplastic carcinomas of the breast may be underpinned by distinct patterns of genetic aberrations. ${ }^{23}$ Further studies investigating the prevalence of intratumour genetic heterogeneity in relation to the presence of mutations of Wnt pathway genes in distinct components of metaplastic breast cancers are warranted.

In conclusion, $\beta$-catenin nuclear expression is a common feature in fibromatosis and in the stromal component of phyllodes tumours, but it may also be observed in metaplastic breast carcinomas. Therefore, $\beta$-catenin nuclear expression should not be used as a single marker to differentiate fibromatosis from other spindle cell tumours of the breast. Despite the presence of $\beta$-catenin nuclear expression in a subgroup of metaplastic breast carcinomas, no exon 3 CTNNB1 gene mutations were found in 21 microdissected metaplastic breast cancers, suggesting that Wnt pathway activation in these tumours may be driven either by mutations in other exons of the CTNNB1 gene or activation/inactivation of other components of the Wnt pathway.

\section{Acknowledgements}

This study was funded in part by the Breakthrough Breast Cancer. Magali Lacroix-Triki was funded by a partenariat grant from the Fédération Nationale des Centres de Lutte Contre le Cancer (FNCLCC, Paris) and the Fondation Médicale de France (Paris). 


\section{Disclosure/conflict of interest}

The authors declare no conflict of interest.

\section{References}

1 Hatsell S, Rowlands T, Hiremath M, et al. Beta-catenin and Tcfs in mammary development and cancer. J Mammary Gland Biol Neoplasia 2003;8:145-158.

$2 \mathrm{He}$ TC, Sparks AB, Rago C, et al. Identification of c-MYC as a target of the APC pathway. Science 1998;281:1509-1512.

3 Lin SY, Xia W, Wang JC, et al. Beta-catenin, a novel prognostic marker for breast cancer: its roles in cyclin D1 expression and cancer progression. Proc Natl Acad Sci USA 2000;97:4262-4266.

4 Tetsu O, McCormick F. Beta-catenin regulates expression of cyclin D1 in colon carcinoma cells. Nature 1999;398:422-426.

5 Deng J, Miller SA, Wang HY, et al. Beta-catenin interacts with and inhibits NF-kappa B in human colon and breast cancer. Cancer Cell 2002;2:323-334.

6 Cui J, Zhou X, Liu Y, et al. Wnt signaling in hepatocellular carcinoma: analysis of mutation and expression of beta-catenin, T-cell factor-4 and glycogen synthase kinase 3-beta genes. J Gastroenterol Hepatol 2003;18:280-287.

7 Hennessy BT, Gonzalez-Angulo AM, Stemke-Hale K, et al. Characterization of a naturally occurring breast cancer subset enriched in epithelial-to-mesenchymal transition and stem cell characteristics. Cancer Res 2009;69:4116-4124.

8 Nagasawa Y, Miyoshi Y, Iwao K, et al. Transformation and morphological changes of murine $\mathrm{L}$ cells by transfection with a mutated form of beta-catenin. Cancer Res 1999;59:3539-3542.

9 Sparks AB, Morin PJ, Vogelstein B, et al. Mutational analysis of the APC/beta-catenin/Tcf pathway in colorectal cancer. Cancer Res 1998;58:1130-1134.

10 Hayes MJ, Thomas D, Emmons A, et al. Genetic changes of Wnt pathway genes are common events in metaplastic carcinomas of the breast. Clin Cancer Res 2008;14:4038-4044.

11 Abraham SC, Reynolds C, Lee JH, et al. Fibromatosis of the breast and mutations involving the APC/betacatenin pathway. Hum Pathol 2002;33:39-46.

12 Sawyer EJ, Hanby AM, Rowan AJ, et al. The Wnt pathway, epithelial-stromal interactions, and malignant progression in phyllodes tumours. J Pathol 2002; 196:437-444.

13 Sawyer EJ, Hanby AM, Poulsom R, et al. Beta-catenin abnormalities and associated insulin-like growth factor overexpression are important in phyllodes tumours and fibroadenomas of the breast. J Pathol 2003;200:627-632.

14 Jara-Lazaro AR, Tan PH. Molecular pathogenesis of progression and recurrence in breast phyllodes tumors. Am J Transl Res 2009;1:23-34.

15 Karim RZ, Gerega SK, Yang YH, et al. Proteins from the Wnt pathway are involved in the pathogenesis and progression of mammary phyllodes tumours. J Clin Pathol 2009;62:1016-1020.

16 Lee AH. Recent developments in the histological diagnosis of spindle cell carcinoma, fibromatosis and phyllodes tumour of the breast. Histopathology 2008;52:45-57.
17 Ng TL, Gown AM, Barry TS, et al. Nuclear beta-catenin in mesenchymal tumors. Mod Pathol 2005;18:68-74.

18 Carlson JW, Fletcher CD. Immunohistochemistry for beta-catenin in the differential diagnosis of spindle cell lesions: analysis of a series and review of the literature. Histopathology 2007;51:509-514.

19 Lazar AJ, Tuvin D, Hajibashi S, et al. Specific mutations in the beta-catenin gene (CTNNB1) correlate with local recurrence in sporadic desmoid tumors. Am J Pathol 2008;173:1518-1527.

20 Miyaki M, Konishi M, Kikuchi-Yanoshita R, et al. Coexistence of somatic and germ-line mutations of APC gene in desmoid tumors from patients with familial adenomatous polyposis. Cancer Res 1993;53:5079-5082.

21 Reis-Filho JS, Milanezi F, Steele D, et al. Metaplastic breast carcinomas are basal-like tumours. Histopathology $2006 ; 49: 10-21$.

22 Turner NC, Reis-Filho JS, Russell AM, et al. BRCA1 dysfunction in sporadic basal-like breast cancer. Oncogene 2007;26:2126-2132.

23 Geyer FC, Weigelt B, Natrajan R, et al. Molecular analysis reveals a genetic basis for the phenotypic diversity of metaplastic breast carcinomas. J Pathol 2010;220:562-573.

24 Reis-Filho JS, Pinheiro C, Lambros MB, et al. EGFR amplification and lack of activating mutations in metaplastic breast carcinomas. J Pathol 2006;209:445-453.

25 Tavassoli FA, Devilee P, eds. Tumours of the Breast. Pathology and Genetics. Tumours of the Breast and Female Genital Organs. International Agency for Research of Cancer (IARC): Lyon, 2003.

26 Dunne B, Lee AH, Pinder SE, et al. An immunohistochemical study of metaplastic spindle cell carcinoma, phyllodes tumor and fibromatosis of the breast. Hum Pathol 2003;34:1009-1015.

27 Harvey JM, Clark GM, Osborne CK, et al. Estrogen receptor status by immunohistochemistry is superior to the ligand-binding assay for predicting response to adjuvant endocrine therapy in breast cancer. J Clin Oncol 1999;17:1474-1481.

28 Marchio C, Iravani M, Natrajan R, et al. Genomic and immunophenotypical characterization of pure micropapillary carcinomas of the breast. J Pathol 2008;215: 398-410.

29 Sekine S, Shibata T, Sakamoto M, et al. Target disruption of the mutant beta-catenin gene in colon cancer cell line HCT116: preservation of its malignant phenotype. Oncogene 2002;21:5906-5911.

30 Weigelt B, Mackay A, A'Hern R, et al. Breast cancer molecular profiling with single sample predictors: a retrospective analysis. Lancet Oncol 2010;11:339-349.

31 Weigelt B, Kreike B, Reis-Filho JS. Metaplastic breast carcinomas are basal-like breast cancers: a genomic profiling analysis. Breast Cancer Res Treat 2009;117: 273-280.

32 Weigelt B, Horlings HM, Kreike B, et al. Refinement of breast cancer classification by molecular characterization of histological special types. J Pathol 2008;216:141-150.

33 Lien HC, Hsiao YH, Lin YS, et al. Molecular signatures of metaplastic carcinoma of the breast by large-scale transcriptional profiling: identification of genes potentially related to epithelial-mesenchymal transition. Oncogene 2007;26:7859-7871.

34 Sarrio D, Rodriguez-Pinilla SM, Hardisson D, et al. Epithelial-mesenchymal transition in breast cancer relates to the basal-like phenotype. Cancer Res 2008; 68:989-997. 